\title{
A Study on Acceptance and Resistance of Smart TVs
}

\author{
Sungjoon Lee \\ Department of Journalism and Communication Studies \\ Cheongju University, Cheongju City 380-764, Korea
}

\begin{abstract}
This study investigated what factors affect consumers' decision making concerning the adoption of smart TVs. For this purpose, the integrated adoption model that consists of six major constructs from the diffusion of innovation theory (DIT), the technology acceptance model (TAM), and the model of innovation resistance(MIR) was employed. To collect data, an online survey was used. Data collected were analyzed with the structural equation model (SEM). Findings showed that the innovativeness has a positive influence on the both of perceived usefulness and perceived ease of use. It was also shown that both of perceived usefulness and perceived ease of use affect the intention to use smart TVs in a positive way. The innovation resistance has a negative influence on the intention to use. The mediating role of the innovation resistance was also found. The implications of these results are discussed.
\end{abstract}

Keywords: Diffusion of Innovation Theory, Technology Acceptance Model, Model of Innovation Resistance, Structural Equation Model, Smart TV

\section{INTRODUCTION}

The development of smart devices of several types in recent years has reshaped existing media usage patterns. Smart TVs, for instance, are the latest type of smart devices and are currently gaining popularity around the world [1]. It was reported that the overall smart TV market was worth $\$ 86$ billion in 2010, and the size of the market is expected to reach $\$ 265$ billion by the end of 2016 with a Compounded Annual Growth Rate (CAGR) of 17\% [2].

The term "smart TV," which is often used as a synonym for the term "connected TV" or "hybrid TV," usually refers to a television set that is integrated with the Internet and Web 2.0 features [3]. Like smart phones, smart TVs allow consumers increased control over content (or applications). In terms of consumer choice, the content of traditional TV has been likened to a "walled garden" in which network operators have overall control over what content is provided [4]. In contrast, smart TV allows consumers to choose from a more diverse range of content and applications based on their own needs by connecting them with new types of distribution channels such as "application stores" and the Internet.

Expecting that the smart TV market will generate tremendous revenues, major TV manufacturers have worked to develop and release several types of smart TVs. For example, Samsung, LG, Sony, and Apple have showcased numerous smart TVs and received spotlight billing at the Consumer Electronics Show (CES) in 2012. At the show, the latest smart TVs had evolved

\footnotetext{
* Corresponding author,E-mail: tcbrad978@cju.ac.kr Manuscript received Apr. 12, 2012; revised Jul 25, 2012; accepted Aug 6, 2012
}

to the extent that they could recognize users' voices and faces [5].

In tandem with the growing interest by many parties, an increasing amount of research on smart TVs is currently being conducted. Until now, most research has focused on the technological aspects of smart TVs, although there have also been studies on the managerial and economic aspects of smart TVs. For instance, Kim and Park studied effective strategies for promoting smart TVs [6], and Moon and Choi conducted an explanatory study of the effect of smart TVs on domestic broadcasting after their introduction in South Korea [7]. However, little is known about how consumers truly feel about smart TVs and what factors affect consumer decision-making concerning the adoption of smart TVs. One particular question that is not well understood is what delays the adoption of smart TVs among consumers [8].

Thus, this study investigates what factors promote or hinder the adoption of smart TVs using a new research model that includes six constructs based on three major adoption frameworks: diffusion of innovation theory (DIT) [9], the technology acceptance model (TAM) [10], and the model of innovation resistance (MIR) [8]. Moreover, the present study attempts to test the usefulness of integrating these three theoretical frameworks.

The results of this research can provide useful practical insight into the appeal of and barriers to smart TV adoption by consumers. In addition, the present study has the potential to help scholars understand the dynamic nature of the adoption process using an integrated theoretical framework rather than an individual theoretical framework. 


\section{BACKGROUND AND LITERATURE REVIEW}

\subsection{Concepts of smart TVs}

There have been several different proposed definitions of smart TVs. Jeong et al. [11] argued that the following features make smart TVs different from conventional television: their open content, entertainment/communication functions, Nscreen service, smart multi-tasking, smart advertisements, and smart home servers. It has been suggested that the word "smart" in the term "smart TV" means "self-customized \& social networked" [12].

Despite these conceptual variations, smart TVs can be understood in general terms as providing conventional broadcasting; Internet access, applications and convergence or intelligent services via a CPU; and an operating platform through the set-top box or display [13]. Smart TVs are often confused with Internet Protocol TV (IPTV) or Web TV. However, some conceptual differences exist between these technologies [14], as shown in Table 1.

Table 1. Comparison between smart TVs and other types of TVs

\begin{tabular}{|c|c|c|c|c|}
\hline & Traditional TV & IPTV & Web TV & Smart TV \\
\hline Channels & Radio/Wave & Internet & Internet & Internet \\
\hline $\begin{array}{l}\text { Two-way } \\
\text { Communication }\end{array}$ & No & $\begin{array}{l}\text { Yes } \\
\text { (partially) }\end{array}$ & Yes & Yes \\
\hline $\begin{array}{l}\text { Quality } \\
\text { of Service }\end{array}$ & Guaranteed & Guaranteed & $\begin{array}{l}\text { Not } \\
\text { Guaranteed }\end{array}$ & $\begin{array}{l}\text { Not } \\
\text { Guaranteed }\end{array}$ \\
\hline Service charge & No & Yes & Yes \& No & Yes \& No \\
\hline $\begin{array}{l}\text { Contents } \\
\text { Provided }\end{array}$ & $\begin{array}{l}\text { Content } \\
\text { secured/produced } \\
\text { by } \\
\text { Service provider }\end{array}$ & $\begin{array}{l}\text { Secured } \\
\text { by service } \\
\text { providers }\end{array}$ & $\begin{array}{l}\text { Online } \\
\text { contents }\end{array}$ & $\begin{array}{l}\text { Online }+ \\
\text { Offline } \\
\text { Contents }\end{array}$ \\
\hline
\end{tabular}

Source: Lim,(2012), "The Current Trends and Forecasts of

Smart TVs", Available at

$<$ http://plum.hufs.ac.kr/hsn2011/pdf/S2-1.pdf $>$

\subsection{Market trends and issue related to Smart TVs}

It has been consistently predicted that the smart TV market will expand in the near future. According to Digital TV News [15], the smart TV market is forecasted to expand to more than 123 million shipments in 2014, yielding a 30\% CAGR from 2010 to 2014. Some sources have even claimed that smart TVs will eventually serve as a home hub through which all electronic and communications devices are used [16].

However, some also view the smart TV market more pessimistically. As Shin et al. [1] noted, smart TVs are still primitive, and they have many problems that must be resolved. As of 2012, the major problems with smart TVs are considered to be difficulties with navigation, limited content (or applications), and frequent malfunctions (or bugs). It was also argued that smart TVs cannot appeal to the majority of customers because televisions are usually considered to be lean-back media [17].

The conflicts between various stakeholders in this market also need to be effectively resolved to ensure a promising future for smart TVs. For instance, Korea Telecom (KT), the major network operator in South Korea, limited access to its network by smart TVs produced by Samsung, the major TV manufacturer. This incident generated discussion about the principle of network neutrality, which allows all consumers to use a service without discrimination [18]. Even though the two parties eventually reached an agreement that required KT to allow network access for users of Samsung's smart TVs, conflicts of this sort are expected to increase in frequency as the growing number of smart devices burden the networks.

\subsection{Theoretical frameworks related to the acceptance and rejection of innovation and integrated models}

Several theoretical frameworks have been proposed to explain the adoptive behavior toward new media technologies. Of these, DIT is one of the most widely used theoretical frameworks [9]. DIT uses a process-oriented perspective to explain how an innovation can be accepted and disseminated among consumers [19]. It contents that five important perceived attributes of innovations (relative advantage, compatibility, complexity, triability, and observability) determine whether people will adopt a new innovation. DIT also argues that innovativeness as a personal trait influences the adoption of new technology [20].

The TAM framework is another framework that has proven to be effective in explaining the adoption of new technology. It basically argues that two major constructs, perceived usefulness and perceived ease of use, can predict the adoption and the usage of new technologies [21].

Even though the DIT and TAM frameworks provide useful insights into why people adopt new technologies and suggest important constructs that affect innovation adoption, research based on these two theoretical frameworks is often criticized for assuming that all innovations are good and should be adopted by everyone. This assumption is referred to as "proinnovation bias." [8] Furthermore, these two theoretical frameworks sometimes do not successfully explain the low rate of diffusion of particular innovations in our society.

On this subject, Ram [8] argued that consumers have a tendency to resist innovation because innovation imposes changes on consumers, suggesting the MIR framework. Ram conceptualized this consumer's tendency using the psychological construct of innovation resistance in his model. Sheth [35] also contended that because the vast majority of consumers have no a priori desire to change, scholars must concentrate more on understanding the reasons for innovation resistance than on examining the reasons for adoption.

In addition to these frameworks, an emerging body of literature has recently suggested an integrated approach to the innovation adoption process. The use of an integrated approach helps researchers to avoid the limitations that are often associated with a single model of innovation adoption. Tung et al. [36] used a new research model that integrated the TAM with the DIT in explaining the adoption of electronic logistic information system in the media industry. The researchers contented that there is a complementary relationship between the DIT and the TAM because whereas some important constructs that influence adoption can be ignored when the TAM framework is used, the DIT framework does not provide appropriate explanations for the causal relationships among the factors influencing adoption. Park [37] also proposed the integrative adoption model of new media to explain adoption 
decision-making regarding social media. In the new model, he integrated the theoretical propositions and empirical results for the DIT, TAM and MIR frameworks. Then, using his new model, he empirically proved the mediating role of innovation resistance in influencing several key constructs from the DIT and TAM. Moreover, he argued that the innovation resistance construct in the MIR should be treated as important together with major constructs from the TAM and DIT because of the intensity of "technology paradoxes" (coexisting consumer expectations and fears about technology) in the current media environment [37].

In this overall context, the present study considers the adoption decision-making process for consumers based on an integrated framework rather than a single model.

\section{RESEARCH MODEL, CONSTRUCTS AND HYPOTHESES}

As mentioned above, this research examines what determinants promote or hinder the adoption of smart TVs based on a new research model that include six key constructs from the DIT, TAM and MIR (See Fig. 1). A detailed explanation of each construct used in the new model is offered in the next sections.

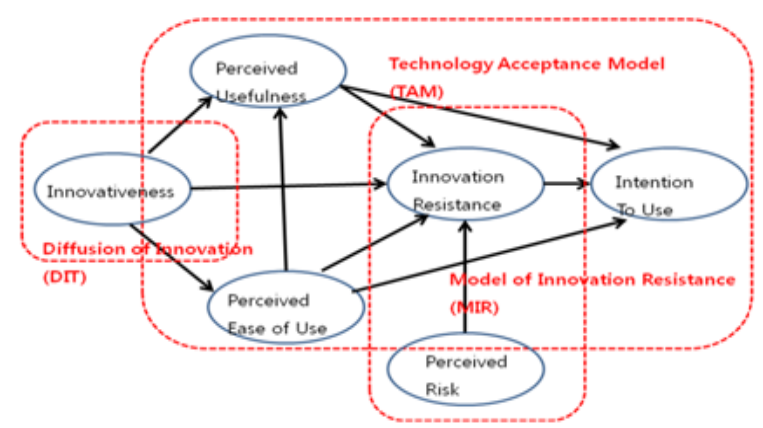

Fig. 1. Research model in this study

\subsection{Innovativeness}

There have been several notable variations in the definition of innovativeness. Rogers and Shoemaker [20] defined innovativeness as the degree of speed with which an innovation is adopted by an individual. In contrast, Midgley and Dowling defined innovativeness as the degree to which an individual makes innovation decisions independently of the experiences communicated by others [22]. A significant body of research has already proven that innovativeness can have a positive influence on the adoption of new technologies [23].

The relationships among innovativeness, perceived usefulness, and perceived ease of use have also been examined in the existing research. Hwang [23] found that individual innovativeness has a positive effect on the perceived ease of use. She explained that when people who are more innovative try a new system, they have an increased belief in their ability to use the technology and thus perceive the technology as easier to use than those who are less innovative. Yang [24] found innovativeness has significant positive effects on perceived usefulness. Similarly, Ram [8] claimed that personal innovativeness can have a significant negative influence on innovation resistance.

\subsection{Perceived usefulness/ Perceived ease of use}

TAM assumes that the decision to adopt a particular technology is determined by two key factors: perceived usefulness and perceived ease of use. Perceived usefulness is defined as the degree to which a person believes that a particular technology will enhance his or her performance at a job or in his or her daily life, whereas perceived ease of use is defined as the degree to which a person believes that using a particular technology will be effortless [10]. Venkatesh [21] claimed that both perceived usefulness and ease of use have a positive influence on the intention to use. The existing research also shows that people tend to perceive technology as more useful when they feel that the technology is easy to use [10].

Similarly, Ram [8] claimed that both perceived usefulness and perceived ease of use reduce innovation resistance.

\subsection{Perceived risk}

Perceived risk can be defined as the extent to which a person is uncertain about the possible negative consequences of a particular activity [25]. Some scholars argued that perceived risk includes financial, performance, social, and physical risk, as well as risks to privacy and the threat of time loss [26]. According to Ram [8], perceptions related to such risks are the most influential constructs for resistance. Unlike communication systems maintained by network operators such as IPTV, which include a dedicated infrastructure and continuous management of network quality, smart TV does not always guarantee network quality. Thus, people's perceptions regarding network quality can increase innovation resistance [27].

\subsection{Innovation resistance}

Innovation resistance can be defined as the consumer resistance to an innovation because it poses potential changes to a satisfactory status quo or because it conflicts with the consumer belief structure [28]. It is noteworthy that innovation resistance is not equivalent to the non-adoption of innovation. According to Kleijnen et al. [29], the concept of innovation resistance can be further subcategorized into three components: rejection, postponement, and opposition. Rejection is a strong disinclination to adopt an innovation that is not driven by a simple lack of awareness or ignorance. In postponement, consumers decide not to adopt an innovation until the circumstances are more suitable although they find the innovation in question to be acceptable in principle. Finally, opposition can be conceptualized as the conviction that the innovation is unsuitable and may include consumer attacks against the launch of the innovation. Resistance and adoption can coexist during the innovation adoption process. In fact, resistance needs to be understood as another factor in the adoption decision process rather than as a determinant that necessarily leads to non-adoption [8]. Several existing studies suggest that innovation resistance has a negative influence on intention to use new technologies [30]. It is also understood that innovation resistance can play a mediating role in the 
adoption process [37].

\subsection{Intention to use}

Intention to use, which can be understood as a plan to adopt and use a particular new media technology, has been widely employed as the dependent variable in TAM instead of actual usage [10]. Davis [10] argued that behavioral intention to use is a major determinant of user behavior, whereas other factors influence user behavior indirectly through behavioral intention, as indicated by existing research [31].

\subsection{Hypotheses proposed in this study}

Based on the literature discussed above, the following nine hypotheses are proposed:

H1: Innovativeness has a positive effect on perceived usefulness.

H2: Innovativeness has a positive effect on perceived ease of use.

H3: Innovativeness has a negative effect on innovation resistance.

H4: Perceived usefulness has a negative effect on innovation resistance.

H5: Perceived usefulness has a positive effect on intention to use.

H6: Perceived ease of use has a negative effect on innovation resistance.

H7: Perceived ease of use has a positive effect on intention to use.

H8: Perceived ease of use has a positive effect on perceived usefulness.

H9: Perceived risk has a positive influence on innovation resistance.

H10: Innovation resistance has a negative influence on intention to use.

\section{METHODOLOGY}

\subsection{Data}

An online survey was administered to panels of the professional research company Embrain (www.embrain.com) from January 10 to 13, 2012. As of 2011, Embrain has 650,000 panels that have been recruited from the South Korean population based on their demographic characteristics (e.g, gender, age, region). The initial sample used in this study was comprised of 680 randomly selected panels.

The individuals in question were contacted via e-mail invitation messages that contained links to an online survey page (http://online.ezsurvey.co.kr). Only those panels that had used smart TVs were selected. A screening questionnaire was used for this purpose.

A total of 300 valid responses (for a $44.1 \%$ effective response rate) were ultimately analyzed in this study. The survey questionnaires consisted of 23 items, among which 18 7-point Likert scale items used to measure 6 constructs in the model. Detailed explanations about these 18 items are shown in Table 2. Demographic information about the respondents was recorded in addition to the construct measurements.
Table 2. Measurement items

\begin{tabular}{|c|c|}
\hline Construct & Descriptions of items \\
\hline INNO 1 & I am willing to take new things/services \\
\hline INNO 2 & $\begin{array}{l}\text { I think it is very interesting to try new things } \\
\text { or services }\end{array}$ \\
\hline INNO 3 & I enjoy trying on new things/services \\
\hline PU 1 & $\begin{array}{l}\text { Using a smart TV can increase the efficacy of } \\
\text { my life }\end{array}$ \\
\hline PU 2 & $\begin{array}{l}\text { Using a smart TV can provide me useful } \\
\text { information in my life }\end{array}$ \\
\hline PU 3 & $\begin{array}{l}\text { I can get various types of information using a } \\
\text { smart TV }\end{array}$ \\
\hline PEOU 1 & It is simple to learn to use a smart $\mathrm{TV}$ \\
\hline PEOU 2 & It is easy to use a smart TV \\
\hline PEOU 3 & $\begin{array}{l}\text { It is easy to become familiar with the use of a } \\
\text { smart TV }\end{array}$ \\
\hline PRSK 1 & $\begin{array}{l}\text { I am concerned that a smart TV sometimes } \\
\text { may not function well }\end{array}$ \\
\hline PRSK 2 & $\begin{array}{l}\text { I am concerned that there may sometimes be } \\
\text { problems with downloading applications } \\
\text { when I use a smart TV }\end{array}$ \\
\hline PRSK 3 & $\begin{array}{l}\text { I am concerned that a smart TV may be } \\
\text { sometimes disconnected. }\end{array}$ \\
\hline IR 1 & A smart TV deserves criticism \\
\hline IR 2 & I feel uneasy when I use a smart TV \\
\hline IR 3 & I tend to oppose against a smart TV \\
\hline INTU 1 & I plan to use a smart TV in the future \\
\hline INTU 2 & I will recommend that others use a smart TV \\
\hline INTU 3 & I will talk about the advantages of a smart TV \\
\hline
\end{tabular}

\subsection{Reliability and validity of measurement}

The Cronbach's alphas were calculated for each construct as shown in table 3. Cronbach's alpha scores for all constructs were above .8 [32], which means all constructs passed the reliability test.

To assess convergent validity, each individual item's factor loading and each construct's Critical Ratio (CR) and Average Variance Extracted (AVE) were tested using the AMOS 18.0. All items exceeded the cutoff point (.70), and the CRs of all six constructs in Table 3 were higher than .70 (AVE higher than .50), which indicated strong convergent validity [33].

Table 3. Results of items' reliabilities, validities and factor loadings

\begin{tabular}{cccccc}
\hline Items & Loading & $\mathrm{p}$-value & $\begin{array}{c}\text { Cronbach's } \\
\text { alpha }\end{array}$ & CR & AVE \\
\hline (INNO) & & & $\mathbf{. 8 6 2}$ & $\mathbf{. 8 3 0}$ & $\mathbf{. 6 2 2}$ \\
\hline INNO 1 & .869 & $\mathrm{p}<.001$ & & & \\
\hline INNO 2 & .759 & $\mathrm{p}<.001$ & & & \\
\hline
\end{tabular}




\begin{tabular}{|c|c|c|c|c|c|}
\hline INNO 3 & .838 & $\mathrm{p}<.001$ & & & \\
\hline (PU) & & & .882 & .880 & .710 \\
\hline PU 1 & .810 & $\mathrm{p}<.001$ & & & \\
\hline PU 2 & .857 & $\mathrm{p}<.001$ & & & \\
\hline PU 3 & .874 & $\mathrm{p}<.001$ & & & \\
\hline (PEOU) & & & .903 & .872 & .696 \\
\hline PEOU 1 & .829 & $\mathrm{p}<.001$ & & & \\
\hline PEOU 2 & .883 & $\mathrm{p}<.001$ & & & \\
\hline PEOU 3 & .899 & $\mathrm{p}<.001$ & & & \\
\hline (PRSK) & & & .919 & .864 & .678 \\
\hline PRSK 1 & .874 & $\mathrm{p}<.001$ & & & \\
\hline PRSK 2 & .909 & $\mathrm{p}<.001$ & & & \\
\hline PRSK 3 & .886 & $\mathrm{p}<.001$ & & & \\
\hline (IR) & & & .906 & .867 & .688 \\
\hline IR 1 & .753 & $\mathrm{p}<.001$ & & & \\
\hline IR 2 & .980 & $\mathrm{p}<.001$ & & & \\
\hline IR 3 & .900 & $\mathrm{p}<.001$ & & & \\
\hline (INTU) & & & .845 & .845 & .645 \\
\hline INTU 1 & .819 & $\mathrm{p}<.001$ & & & \\
\hline INTU 2 & .853 & $\mathrm{p}<.001$ & & & \\
\hline INTU 3 & .905 & $\mathrm{p}<.001$ & & & \\
\hline
\end{tabular}

(comparative fit index), also indicated the adequate fit of the measurement model $(\mathrm{GFI}=.903, \mathrm{CFI}=.957)$.

\subsection{Data analysis procedures of the research model}

The structural model was evaluated using maximum likelihood in AMOS 18.0. This process yielded two critical pieces of information that indicated how well the structural model predicted the hypothesized relationships. The first piece of information was the construct's percentage of variation explained by the model. The second essential type of information generated by AMOS 18.0 was the path coefficients, which indicated the strength of the relationship between two constructs.

\section{RESULTS}

\subsection{Sample characteristics}

Table 5 shows the profile of the sample respondents, including their demographic information. Of the subjects, $58.3 \%$ were males and $41.7 \%$ were female. The majority of respondents were in their $30 \mathrm{~s}(30.0 \%)$ and they were mainly office workers $(35.0 \%)$; more than $80 \%$ of people had undergone higher education including postgraduate study, and $26.0 \%$ had a monthly household income between US $\$ 2,800$ and $\$ 3,800$

Table 5. Profiles of sample respondents

The discriminant validity was also examined. As shown in Table 4, the square root of every AVE were greater than the correlations between the corresponding constructs, and the confidence interval of the coefficients did not include 1.0, which indicated the discriminant validity of the constructs [34].

Table 4. Correlations of the latent variables and standard errors

\begin{tabular}{|c|c|c|c|c|c|c|}
\hline & INNO & $\mathrm{PU}$ & PEOU & PRSK & IR & UNIT \\
\hline INNO & .789 & & & & & \\
\hline PU & $\begin{array}{l}.474 \\
(.66)\end{array}$ & .843 & & & & \\
\hline PEOU & $\begin{array}{l}.556 \\
(.80)\end{array}$ & $\begin{array}{l}.576 \\
(.074)\end{array}$ & .834 & & & \\
\hline PRSK & $\begin{array}{l}.178 \\
(.078) \\
\end{array}$ & $\begin{array}{l}.061 \\
(.080) \\
\end{array}$ & $\begin{array}{l}.019 \\
(.082) \\
\end{array}$ & .823 & & \\
\hline IR & $\begin{array}{l}.223 \\
(.078)\end{array}$ & $\begin{array}{l}. .440 \\
(.075)\end{array}$ & $\begin{array}{l}.242 \\
(.083)\end{array}$ & $\begin{array}{l}.323 \\
(.093)\end{array}$ & .829 & \\
\hline INTU & $\begin{array}{l}.461 \\
(.078)\end{array}$ & $\begin{array}{l}.706 \\
(.081)\end{array}$ & $\begin{array}{l}.628 \\
(.087)\end{array}$ & $\begin{array}{l}-.046 \\
(.085)\end{array}$ & $\begin{array}{l}.527 \\
(.090)\end{array}$ & .803 \\
\hline
\end{tabular}

Note. The numbers in parentheses indicate the standard errors.

The diagonal value in this table indicates the square root of the AVE.

Several goodness of fit measures also indicated the good of fit of the measurement model. First, the value of $\times 2$ indicates a good fit $(x 2=289.766, \mathrm{df}=120, \mathrm{p}<.001)$. Other measures such as the GFI (goodness of fit index) and the CFI

\begin{tabular}{|c|c|c|c|}
\hline & Category & Frequency & Percentage \\
\hline \multirow[t]{2}{*}{ Gender } & Male & 175 & 58.3 \\
\hline & Female & 125 & 41.7 \\
\hline \multirow[t]{4}{*}{ Age } & $20-29$ & 82 & 27.4 \\
\hline & $30-39$ & 90 & 30.0 \\
\hline & $40-49$ & 63 & 21.0 \\
\hline & $50-59$ & 65 & 21.7 \\
\hline \multirow[t]{10}{*}{ Occupation } & Student & 35 & 11.7 \\
\hline & $\begin{array}{l}\text { Civil } \\
\text { servant }\end{array}$ & 11 & 3.7 \\
\hline & Salesman & 16 & 5.3 \\
\hline & $\begin{array}{l}\text { Office } \\
\text { worker }\end{array}$ & 105 & 35.0 \\
\hline & $\begin{array}{l}\text { Self- } \\
\text { employed }\end{array}$ & 34 & 11.3 \\
\hline & Housewife & 43 & 14.3 \\
\hline & Researcher & 6 & 2.0 \\
\hline & Engineer & 34 & 11.3 \\
\hline & Teacher & 10 & 3.3 \\
\hline & Other & 6 & 2.0 \\
\hline \multirow[t]{3}{*}{$\begin{array}{l}\text { Educational } \\
\text { Level }\end{array}$} & $\begin{array}{l}\text { High } \\
\text { school or } \\
\text { below }\end{array}$ & 47 & 15.7 \\
\hline & College & 224 & 74.7 \\
\hline & Advanced & 29 & 9.7 \\
\hline
\end{tabular}




\begin{tabular}{llll}
\hline \multicolumn{3}{c}{ Degree } & \\
$\begin{array}{l}\text { Household } \\
\text { Income }\end{array}$ & $\$ 800-1800$ & 28 & 9.3 \\
\hline & $\begin{array}{l}\$ 1800- \\
2800\end{array}$ & 61 & 20.3 \\
\hline $\begin{array}{l}\$ 2800- \\
3800\end{array}$ & 78 & 26.0 \\
\hline $\begin{array}{l}\$ 3800- \\
4800\end{array}$ & 55 & 18.3 \\
\hline $\begin{array}{l}\$ 4800- \\
5800\end{array}$ & 30 & 10.0 \\
\hline $\begin{array}{l}\$ 5800- \\
6800\end{array}$ & 8 & 2.7 \\
\hline $\begin{array}{l}\$ 6800- \\
7800\end{array}$ & 13 & 4.3 \\
\hline $\begin{array}{l}\text { Above } \\
\$ 7800\end{array}$ & 27 & 9.0 \\
\hline
\end{tabular}

\subsection{Evaluation of structural model}

The hypothesized model was assessed as follows. First, the goodness of fit of the hypothesized research model was tested. This is typically done using a chi-square $(x 2)$ test. The value of $\mathrm{x} 2$ indicates the fit of the hypothesized research model $(\mathrm{x} 2=$ $313.35, \mathrm{df}=125, \mathrm{p}<0.001)$. However, a chi-square test is sensitive to sample size, so supplemental tests including the GFI and CFI were also used. It is widely accepted that a good fit is indicated by GFI and CFI values higher than 0.9 [34]. The hypothesized research model has a GFI of .900 and a CFI of .949 , which together indicate the relatively good fit of the model.

\subsection{Hypotheses testing}

Table 6 and Fig. 2 summarize the results for the tested hypotheses. Two of the hypotheses (H3, H6) were rejected, whereas the others were supported. Individual innovativeness has a significant positive effect on the perceived usefulness (H1) $(\beta=.186, \mathrm{p}<.01)$ and on the perceived ease of use $(\mathrm{H} 2)(\beta$ $=.551, \mathrm{p}<.001)$, but, it did not have a statistically significant effect on innovation resistance $(\mathrm{H} 3)(\beta=-.068$, n. s.).

Table 6. Summary of Hypothesis Testing

\begin{tabular}{lll}
\hline Hypothesis & Supported & $\begin{array}{l}\text { Standardized } \\
\text { Coefficient }\end{array}$ \\
\hline H1: INNO -> PU & YES & $.186(3.287)^{* *}$ \\
\hline $\begin{array}{l}\text { H2: INNO -> } \\
\text { PEOU }\end{array}$ & YES & $.551(8.801)^{* * *}$ \\
\hline H3: INNO -> IR & NO & $-.068(-.953)$ \\
\hline H4: PU -> IR & YES & $-469(-4.951)^{* * *}$ \\
\hline H5: PU -> INTU & YES & $.661(7.244)^{* * *}$ \\
\hline H6: PEOU -> IR & NO & $.076(.984)$ \\
\hline $\begin{array}{l}\text { H7: PEOU -> } \\
\text { INTU }\end{array}$ & YES & $.198(3.116)^{* *}$ \\
\hline H8: PEOU -> PU & YES & $.367(6.207)^{* * *}$ \\
\hline
\end{tabular}

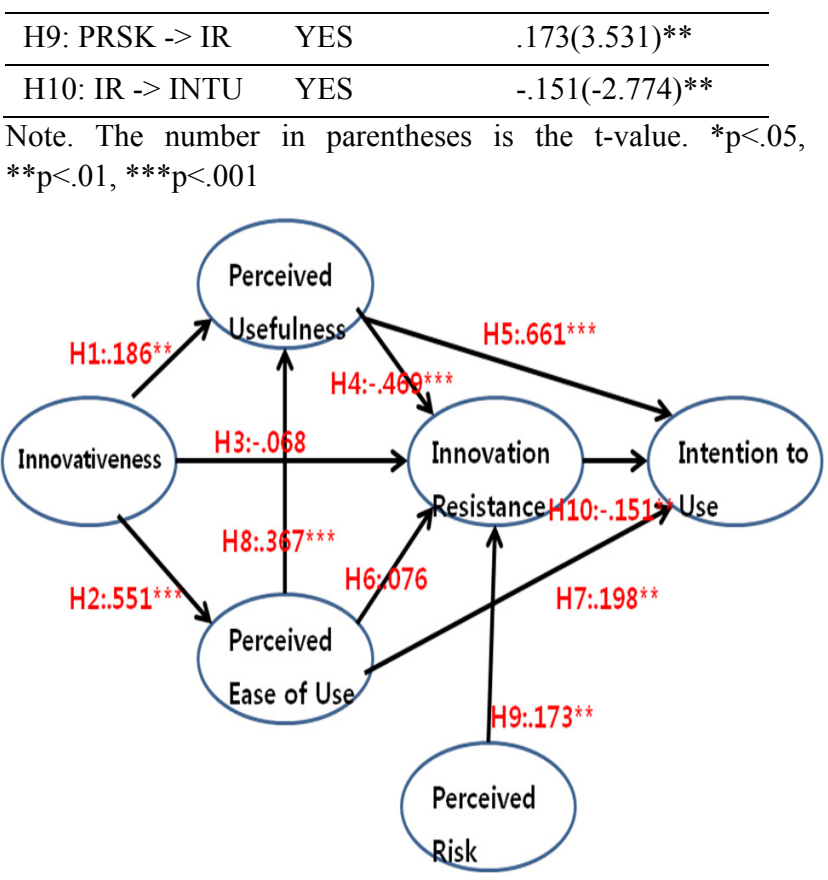

Fig. 2. The results of this study

The perceived usefulness has a significant negative effect on innovation resistance $(\mathrm{H} 4)(\beta=-.469, \mathrm{p}<.001)$, and a significant positive effect on intention to use (H5) $(\beta=.661$, $\mathrm{p}<.001)$.

The perceived ease of use has a significant positive effect on both the intention to use $(\mathrm{H} 7)(B=.198, \mathrm{p}<.01)$ and the perceived usefulness $(\mathrm{H} 8)(\beta=.367, \mathrm{p}<.001)$. However, the perceived ease of use does not have a significant negative effect on innovation resistance (H6) $(\beta=.076$, n.s.).

The perceived risk has a significant positive effect on innovation resistance $(\mathrm{H} 9)(\beta=.173, \mathrm{p}<.01)$, and innovation resistance has a significant negative effect on intention to use (H10) $(B=-.151, \mathrm{p}<.01)$.

\section{DISCUSSION AND CONCLUSION}

The first aim of the current study was to identify the factors that have positive effects on user adoption of smart TVs. The findings indicated that innovativeness (as taken from the DIT) is an important factor that affects the perceived ease of use and perceived usefulness ( $\mathrm{H} 1$ and $\mathrm{H} 2)$. This idea is consistent with Hwang's [23] argument that the innovativeness of consumers affects their beliefs regarding their technological capabilities, which in turn influences the perceived ease of use of technology. Moreover, this result implies that certain types of consumer characteristics, such as personality and motivation, can influence consumer perception regarding innovation characteristics. It also provides practical guidelines for corporate strategies regarding smart TVs, suggesting the need for companies to target high-innovativeness groups.

Moreover, the findings of this study generally supported hypotheses derived from the TAM framework. This study confirmed that both perceived usefulness and perceived ease of use have a significant positive influence on the intention to use 
(H5 and H7). The relationship between perceived ease of use and perceived usefulness was also identified (H8). As hypothesized, perceived ease of use has a significant positive influence on perceived usefulness. These results indicate that people are willing to use smart TVs when they perceive them as useful in their lives. In addition, the results imply that smart TVs can be more broadly disseminated when people feel that they are easy to use. Thus, the user interface for smart TVs needs to be continuously improved so that people feel that it is easy to use and so that dissemination increases.

Although the DIT and TAM frameworks provide insights into what determinants promote the use of smart TVs, these two frameworks do not indicate why particular groups have not adopted smart TVs effectively. To address this question, the present study attempts to use an integrated model that includes innovation resistance from the MIR framework. The findings show that innovation resistance plays a crucial role in the adoption process. Innovation resistance directly or indirectly counterbalanced the positive influence of perceived usefulness on intention to use (H4 and H10). In other words, if the extent of the facilitating conditions (e.g., perceived usefulness) is less than the extent to which innovation resistance encourages users to reject, postpone or oppose adoption, it is more likely that people may not adopt new technologies. If not, the reverse is true. These results are significant because they explain why the integrated model has advantages over the DIT or TAM in explaining the adoption process as a single framework. Consumers do not always perceive innovation as good, and they also consider the negative aspects of innovation as much as they do the positive ones.

In addition, this study confirms that perceived risk increases innovation resistance (H9). This finding indicates the factors that actually cause users to hesitate to use smart TVs. In this study, the expected network quality was a particularly strong predictor of innovation resistance. Thus, it would seem that smart TVs can be more easily adopted when people have more confidence in the network quality. If consumers do not expect network quality to improve, then they may likely continue to use existing communication technologies.

In this study, the influence of innovativeness and perceived ease of use on innovation resistance was not demonstrated (H3 and H6). These results were inconsistent with previous findings [8] and encourage further investigation of the relationship between innovation resistance and innovativeness (and perceived ease of use).

In summary, this study enriches our understanding of the new media technology adoption process using a new integrated adoption model. Specifically, the present study suggests that it is limiting and sometimes dangerous to assume that all innovations are naturally good and should be adopted by all members of society. Rather, this study emphasizes that people may not be able to adopt innovations for a variety of reasons. Moreover, this research provides practical guidelines for corporate strategies for smart TVs by identifying several factors that influence the adoption process.

The limitations of the current study are critical. This study employed an online survey to collect the data. It is widely understood that online samples may not be representative of the general population, and it has been suggested that online samples may exhibit higher innovativeness than the general population. Thus, the model will be better validated if more representative samples are used in the future.

Another limitation is that the current study conceptualized perceived risk in the context of smart TV adoption simply as related to network quality. As previously discussed, perceived risk actually includes several components. In fact, it is conceivable that other types of components, such as financial risk or privacy risk (rather than network quality), increase innovation resistance in the smart TV adoption process, as is the case with other new media technologies [27]. Future studies must consider the influence of several types of risk in the adoption process.

Finally, future research should include more determinants that affect either perceived usefulness or innovation resistance.

\section{REFERENCES}

[1] D.H. Shin, Y.S. Hwang, and H. Choo, "Smart TV: Are They Really Smart in Interacting with People? Understanding the Interactivity of Korean Smart TV", Behavior \& Information Technology, In press.

[2] Marketpublisher, Global Smart/Connected/Hybrid TV Market Forecast by Accessories, Platforms, Middleware, Application \& Geography Analysis 2011-2016, http://marketpublisher.com/report/technologies_electroni cs/semiconductors/global_smartconnectedhybrid_tv_mar ket_forecast_by_accessories_platforms_middleware_appl ication_geography_analysis_2011_2016.htm.

[3] Wikipeia, Smart TV, http://en.wikipedia.org/wiki/smart_TV.

[4] J. West, and M. Mace, "Browsing as the Killer App: Explaining the Rapid Success of Apple's iphone", Telecommunications Policy, vol. 34, no. 5, 2010, pp. 270-286.

[5] SmartMediaPlatfomrs, Samsung's New Smart TV has Facial, Voice Recognition, http://www.smartmediaplat forms.com/news/Samsungs-new-smart-tv-has-facialvoice-recognition.html.

[6] M. K. Kim, and J.H. Park, "Demand Forecasting and Strategies for the Successful Deployment of the Smart TV in Korea", Advanced Communication Technology, 2011, pp. 1475-1478.

[7] C.-S. Moon, and M.-J. Choi, "The Explanatory Study on the Effect of Smart TV Appearance on Domestic Broadcasting Environment", Korean Journal of Broadcasting and Telecommunication Studies, vol. 73, Dec. 2010, pp. 147-170.

[8] S. Ram, "A Model of Innovation Resistance", Advanced in Consumer Research XIV, 1987, pp. 208-212.

[9] E. M. Rogers, Diffusion of Innovation, Free Press, New York, 1995.

[10] F. D. Davis, "Perceived Usefulness, Perceived Ease of Use, and User Acceptance of Information Technology", MIS Quarterly, vol. 13, no.5, 1989, pp. 319-340.

[11] J. W. Jeong, H. Hong, and D. Lee, “Ontology-based Automatic Video Annotation Technique in Smart TV Environment", IEEE Transactions on Consumer 
Electronics, vol. 57, no. 4, 2010, pp.1830-1836.

[12] LG Business Insights, The Difference in Their Evolutions between Smartphones and Smart TVs, http://www.lgeri.com/industry/electronic/articleasp?grou ping-01030200\&seq $=486$.

[13] Digieco, Trend and Implication of the Media Market Change Caused by Evolution into Smart TV, http://www.digieco.co.kr/KTFront/report/report_strategy _view.action?board_seq $=3971 \&$ board_id $=$ strategy.

[14] J. Lim, The Current Trend and Forecast of Smart TV, http://plum.hufs.ac.kr/hsn2011/pdf/S2-1.pdf.

[15] Digitalnews.net, Connected TVs Forecast to Exceed 123M Units in 2014, http://www.digtalnews.net/content/? $\mathrm{p}=18961$.

[16] Jupiter Research, Prospect of STV, Jupiter Research Inc, Boston, 2010.

[17] Digieco, Transformation of TV, Smart TV, $\mathrm{http}: / /$ www.digieco.co.kr/KTFfront/report_report_issue trend_view.action?board $=$ seq $=6425 \&$ board_id=issue_tre nd.

[18] Koreatimes, KT to Limit Access of Smart TVs to Its Network,

http://www.koreatimes.co.kr/www/news/biz/2012/02/123 104529.html.

[19] C. Yu, and Y. Tao, "Understanding Business-Level Innovation Technology Adoption", Technovation, vol. 29, 2009, pp. 92-109.

[20] E. M. Rogers, and F. Shoemaker, Diffusion of Innovation, Free Press, New York, 1971.

[21] V. Venkatesh, "Technology Acceptance Model 3 and A Research Agenda on Intervention", Decision Sciences, vol. 39, no. 2, 2008, pp. 273-315.

[22] D. F. Midgely, and G. R. Dowling, "Innovativeness: The Concept and Its Measurement", Journal of Consumer Research, vol. 4, 1978, pp. 229-242.

[23] Y. Hwang, "The Impact of Uncertainty Avoidance, Social Norms and Innovativeness on Trust and Ease of Use in Electronic Customer Relationship Management", Electron Markets, vol. 19, no. 2, 2009, pp. 89-98.

[24] K. Yang, "The Effects of Technology Self-Efficacy and Innovativeness on Consumer Mobile Data Service Adoption between American and Korean Consumers", Journal of International Consumer Marketing, vol. 22, no. 2, 2010, pp. 117-127.

[25] M. S. Featherman, and P. A. Pavlou, "Predicting Eservices Adoption: A Perceived Risk Facets Perspectives", International Journal of Human-Computer Studies, vol. 59, no.4, 2003, pp. 451-474.

[26] M, Lee., "Factors Influencing the Adoption of Internet Banking: An Integration of TAM and TPB with Perceived Risk and Perceived Benefit", Electronic Commerce Research and Application, vol. 8, no. 3, 2009, pp. 130-141.

[27] Y. Kang, and S. Kim, "Understanding User Resistance to Participation in Multihop Communication", Journal of Computer-Mediated Communication, vol. 14, no. 2, 2009, pp. 328-351.

[28] S. Ram, and J. N. Sheth, "Consumer Resistance to Innovations: The Marketing Problems and Its Solutions",
Journal of Consumer Marketing, vol. 6, no. 2, 1989, pp. $5-14$

[29] M. Kleijnen, N. Lee, and M. Wetzels, "An Exploration of Consumer Resistance to Innovation and Its Antecedents", Journal of Economic Psychology, vol. 30, no. 3, 2009, pp. $1-14$.

[30] T. Laukkanen, S. Sinkkonen, M. Kivijaryi, and P. Laukkanen, "Innovation Resistance among Mature Consumers", Journal of Consumer Marketing, vol. 24, no. 7, 2007, pp. 419-427.

[31] H. Lee, J. Ryu, D. Kim, and S. Lee, "Acceptance and Rejection of Mobile TV among Young Adults: A Case of College Students in South Korea", Telematics and Informatics, vol. 28, no. 4, 2011, pp. 239-250.

[32] M. W. Browne, and R. Cudeck, "Alternative Ways of Assessing Model Fit", Sociology Methods \& Assessing Model Fit, vol. 21, no. 2, 1992, pp. 230-258.

[33] C. Fornell, and D. F. Larker, "Evaluating Structural Equation Models with Unobserved Variable and Measurement Error", Journal of Marketing, vol. 18, no. 1, 1981, pp. 39-50.

[34] J. C. Anderson, and D. W.Gerbing, "Structural Equation Modeling in Practice: A Review and Recommended Two-Step Approache", Psychological Bulletin, vol. 103, no. 2,1988 , pp. 411-423.

[35] J. N. Sheth, "Psychology of Innovation Resistance: the Less Developed Concept (LDC), in Diffusion Research", Research in Marketing, vol. 4, no. 3, pp. 273-282.

[36] F-C. Tung, S-C. Chang, and C-H. Chou, "An Extension of Trust and TAM model with DIT in the Adoption of the Electronic Logistics Information System in HIS in the Medical Industry", International Journal of Medical Informatics, vol. 77, 2008, 324-335.

[37] B. Park, "Integrated Adoption Model of New Media", Korean Journal of Journalism and Communication Studies, vol. 55, no. 5, 2011, 449-479.

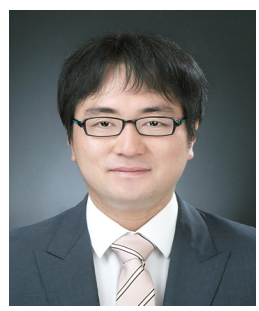

\section{Sungjoon Lee}

$\mathrm{He}$ received his $\mathrm{Ph} . \mathrm{D}$. in communication studies from the State University of New York at Buffalo, USA in 2008. He has been an assistant professor of the department of journalism and communication studies at Cheongju University since 2011. His main research interests include social media, semantic network, communications policy and technology adoption. 